\section{Hepatitis A: a giant leap forward}

\author{
from Arie J. Zuckerman
}

THE past decade has seen rapid progress in the identification of viruses causing hepatitis in man, starting in 1968 with the discovery of the association between Australia antigen and hepatitis type B (serum hepatitis). Five years later, hepatitis A virus, which is the cause of infectious or epidemic hepatitis, was identified by electron microscopy in faecal extracts, and more recently evidence has been obtained of a third type of hepatitis (so called non-A, non-B hepatitis) which is probably caused by more than one virus. The worldwide research effort which has been devoted to the problem of viral hepatitis by epidemiologists, virologists, molecular biologists, immunologists, pathologists, clinicians, blood transfusion services, public health authorities and others reflects the impact which these viruses have on human health and welfare. Although remarkable advances have been made in the characterisation of the biophysical and biochemical properties of hepatitis A and B viruses, reproducible propagation of these viruses in tissue culture has defied every effort and continued to elude even the most stubborn research worker. Provost and Hilleman (Proc. Soc. exp. Biol. Med. 160, 213; 1979) now report the first reliable serial cultivation of human hepatitis A virus in primary explant liver cell cultures of marmosets and in a fetal rhesus kidney cell line. This work represents a spectacular advance in a hitherto frustrating and seemingly insoluble problem.

The events which led to this success started in 1967 when Deinhardt and his associates ( $J$. exp. Med. 125, 673; 1967) transmitted human hepatitis A virus to two species of marmosets, which are small South American monkeys, and the infection was transferred serially from animal to animal. Differences in susceptibility to hepatitis A exist between the marmoset species, with Saguinus mystax being the most susceptible. In 1973, the CR 326 strain of hepatitis A virus was isolated in S. mystax by Mascoli et al. (Proc. Soc. exp. Biol. Med. 142, 276; 1973) from naturally occurring outbreaks in Costa Rica, and the virus was further characterised in the sera and livers of

Arie J. Zuckerman is Professor and Director of the Department of Medical Microbiology and the WHO Collaborating Centre for Reference and Research on $V$ iral Hepatitis at the London School of Hygiene and Tropical Medicine, University of London. the marmosets (Provost et al. Proc. Soc. exp. Biol. Med. 148, 532; 1975). By then sensitive serological tests for hepatitis $A$ virus and its antibody became available and the susceptibility of chimpanzees as well as the susceptibility of a more readily available rufiventer-like marmoset designated as S. labiatus (also known as Marikina labiata, Jacchus rufiventer) was described (Provost et al. Proc. Soc. exp. Biol. Med. 155, 283; 1977).

Using the CR 326 strain of human hepatitis $\mathrm{A}$ virus passaged five times in $S$. mystax and 26 times in S. labiatus, Provost and Hilleman inoculated normal liver explant cell cultures obtained from $S$. labiatus with the virus, and observed by direct immunofluorescence minute fluorescing cytoplasmic granules in some of the hepatocyte-like epithelial cell outgrowths as early as 8 days after inoculation. The number of the affected hepatocyte-like cells and the number of fluorescent granules increased with time so that when cultures were collected on day 23,75 $100 \%$ of these cells, but not other cell types, contained large numbers of granules. There were no cytopathic changes. The virus was identified as hepatitis $\mathrm{A}$ by various techniques including specific immunofluorescence blocking, serum neutralisation, immune adherence haemagglutination and radioimmunoassay; and the virus was passaged serially five times. Because the availability of marmosets is very limited, an alternative cell culture system was sought. The virus propagated in primary kidney cell cultures of Cercopithicus aethiops (grivet or green monkey), but many of the cultures contained cytopathic adventitious agents of endogenous origin. Consequently, Provost and Hilleman used cultures of fetal rhesus kidney cells (designated FRhK6 cell line), which are epithelial-like but have only a maximum population doubling of 12 . Specific immunofluorescence was detected in these cells as early as 3 days after inoculation and occurred throughout the cell sheets during the following weeks. Cytopathic changes were not observed. The virus was passaged serially, the incubation period for development of fluorescence was shortened, and there was a larger yield in these cells than in the liver cell explants. Titration of infectivity of the virus collected in the fifth and sixth passage yielded titres of $10^{6}-10^{7}$ infectious units per $\mathrm{ml}$ respectively, and virus in the fifth passage collection retained the ability to infect $S$. labiatus marmosets. The virus was successfully transferred through eight serial passages in which the calculated dilution of the original inoculum was $2.9 \times 10^{-28}$.
The importance and practical significance of this work can be summarised as follows: the means may now be available for detecting human hepatitis A virus in vitro, for preparing large quantities of viral antigen for serological tests and for providing a source of viral antigen for the preparation of vaccines against an important infection which is endemic in all parts of the world.

However, answers to several questions are still required. Can the virus be cultivated from naturally occurring strains without adaptation by serial passage through susceptible marmosets and what is the minimum period of adaptation required; can hepatitis $\mathbf{A}$ virus be propagated in more readily available cell lines with longer population doubling times? Provost and Hilleman provide a hint that this may be so because the virus replicated to a limited extent in human diploid lung fibroblasts, which are commonly used for the preparation of vaccines. The way may thus be open in the near future to the effective control of epidemic hepatitis.

\section{Vacancies in nickel- aluminium and other alloys}

\section{from Robert W. Cahn}

IN 1937 the metallurgist A. Taylor made a celebrated study of the structure of nickel-aluminium alloys; this called for great experimental precision, and in 1972 he returned to the problem and examined it with even greater scruple (Taylor and Doyle, J. appl. Cryst. 5, 201; 1972). This second study may be said to have launched a new wave of research on the $\mathrm{Ni}-\mathrm{Al}$ system and its analogues, even though few of the most recent protagonists seem to be aware of Taylor's second study.

Taylor's experiments centred on the alloy $\beta$-NiAl, which adopts the very simple B2 (CsCl-type) structure: nickel atoms at cube corners, aluminium at cube centres. Taylor measured macroscopic densities and lattice parameters as a function of composition, either side of the 50/50 composition: by putting together the two sets of measurements, he was able to deduce the destinations of excess nickel or aluminium atoms. On the nickel-rich side, the extra nickel atoms substitute in the usual way for aluminium atoms on the aluminium sublattice. The aluminium-rich side, however, is quite different: no aluminium substitutes on the nickel sublattice, instead nickel atoms disappear from the nickel sublattice, leaving nickel vacancies. For instance, at 45 